\title{
Growth of carbon nanotube filaments on carbon fiber cloth by catalytic chemical vapor deposition
}

\author{
B. P. Singh • Veena Choudhary $\cdot$ V. N. Singh • \\ R. B. Mathur
}

Received: 5 September 2013/Accepted: 30 October 2013/Published online: 13 November 2013

(C) The Author(s) 2013. This article is published with open access at Springerlink.com

\begin{abstract}
Multiwalled carbon nanotube (MWCNT) filaments were grown by catalytic chemical vapor deposition on 2-D weave carbon fiber (CF) cloth substrates. Two different sets of experiments were carried out to understand the growth mechanism of these filaments. In the first set of experiments where $\mathrm{CF}$ cloths were coated with the catalysts particles, CNT filaments having long length $(>200 \mu \mathrm{m})$ and large diameter $(15-25 \mu \mathrm{m})$ were obtained. In another set of experiment, where CF cloths without catalyst particles were used, only MWCNTs without any filament formation were obtained. On the basis of the results, a growth mechanism has been proposed. These MWCNT filaments can be used for preparing CNTs reinforced polymer composites having very good structural properties, which are being sought after.
\end{abstract}

Keywords Carbon filaments $\cdot$ MWCNTs $\cdot$ Chemical vapor deposition

B. P. Singh $(\bowtie) \cdot$ R. B. Mathur

Physics and Engineering of Carbon, Division of Materials

Physics and Engineering, CSIR-National Physical Laboratory,

New Delhi, India

e-mail: bps@mail.nplindia.org

B. P. Singh · V. Choudhary

Centre for Polymer Science and Engineering, Indian Institute of Technology Delhi, Delhi 16, India

V. N. Singh

Electron and Ion Microscopy Section, CSIR-National Physical Laboratory, New Delhi 110012, India

\section{Introduction}

Carbon nanotube (CNT), a fascinating material with outstanding properties has inspired the scientist, engineer and technologist because of its wide range of potential applications (Ajayan and Zhou 2000) in many areas. To utilize their properties for industrial applications, producing high quality CNT on larger scale is necessary. Several methods for the synthesis of CNTs, such as, arc discharge (Choudhary et al. 2013; Mathur et al. 2007), laser ablation (Choudhary et al. 2013; Guo et al. 1995) and chemical vapor deposition (CVD) (Choudhary et al. 2013; Mathur et al. 2008) have been developed. These methods have been further modified to synthesize single walled carbon nanotubes (SWNTs) (Dai et al. 1996; Ebbesen and Ajayan 1992; Thess et al. 1996) and multiwalled carbon nanotubes (MWCNTs) (Chhowalla et al. 2001; Ebbesen et al. 1993). For various specialized applications in electronic devices and composites, CNTs having aligned and controlled structure are required. CVD technique is very useful for producing such structures. Various CVD methods have been developed for synthesizing SWCNTs as well as MWCNT, such as, catalytic CVD or thermal CVD, plasma enhanced CVD (PECVD) (Cheng et al. 1998) and floating catalyst CVD method (Ago et al. 2005; Chen et al. 2006). In the CVD process, organic compounds are decomposed in the presence of catalyst. In the catalytic CVD and PECVD, CNTs growth takes place on the substrate. But in the floating catalyst technique, large quantity of CNTs is generated without use of any substrate. Therefore, the floating catalyst technique is very competitive for producing CNT on large scale for industrial applications. But, controlling the size and composition of the catalyst nanoparticles is a major issue for this technique (Andrews et al. 1999). 
Incorporation of carbon nanotubes (CNTs) into a polymer matrix can improve various properties including mechanical (Ruban et al. 2013; Lubineau and Rahaman 2012; Mathur et al. 2010, 2012; Singh et al. 2012a), electrical (Gupta et al. 2013a, b; Pande et al. 2009a, b; Singh et al. 2011, 2013a, b), thermal (Biercuk et al. 2002; Shenogin et al. 2004; Meenakshi and Sudhan 2011; Singh et al. 2008) and biosensing properties (Dhand et al. 2008; Singh et al. 2012b). CNTs have excellent mechanical properties. Tensile strength of 10-500 GPa and Young's modulus of 0.3-1.0 TPa have been reported (Xie et al. 2005). Several works related to CNTs reinforced polymer composites for structural applications have been reported (Jindal et al. 2013; Lubineau and Rahaman 2012; Mathur et al. 2012; Singh et al. 2013a; Xie et al. 2005). Breakthrough in the CNT-polymer composite properties is still awaited, as it had not achieved the values reported for carbon fiber (CF) reinforced polymer composites. There are several reports on the growth of long fibers made from CNT. But most of them are made by spinning of CNT into fibers. In one such study, Zhang et al. (2004) achieved yarn strengths $>460 \mathrm{MPa}$ by introducing twist during spinning of MWCNTs. In other study, Ericson et al. (2004) produced well-aligned macroscopic fibers composed of SWNTs by conventional spinning. They used solution spinning to grow macroscopic neat SWNT fibers. Li et al. (2004) spun fibers and ribbons of CNT directly from the CVD synthesis zone of a furnace using a liquid source of carbon and an iron nanocatalyst. The process was realized through the appropriate choice of reactants, control of the reaction conditions and continuous withdrawal of the product using a rotating spindle.

Herein, we report another simple method for producing long MWCNT filaments having length $>200 \mu \mathrm{m}$, diameter up to $25 \mu \mathrm{m}$ and consisting of several hundreds of MWCNTs which might be a possible CNTs-based materials to realize the optimum mechanical properties when mixed in polymer matrix.

\section{Experimental}

Synthesis

Two different sets of experiments were performed for the growth of MWCNTs on CF cloth (code 6341, woven from T-300 CF tows) obtained from Toray, Japan. In one set of experiments, first, $8 \mathrm{wt} \%$ ferrocene was dissolved into toluene by ultrasonication (Choudhary et al. 2013; Mathur et al. 2008). The as received CF cloth having $200 \times 50 \mathrm{~mm}$ sizes were dipped in the toluene-ferrocene solution to deposit ferrocene on the cloth. Toluene was evaporated by keeping the $\mathrm{CF}$ cloth in vacuum oven for $4 \mathrm{~h}$ at $80{ }^{\circ} \mathrm{C}$. After drying the cloth, it was placed in the furnace for the deposition of MWCNTs. The reaction zone of the furnace was maintained at $750{ }^{\circ} \mathrm{C}$. Once the temperature was reached, the solution containing a mixture of ferrocene and toluene in particular proportion $(0.077 \mathrm{~g}$ ferrocene in $1 \mathrm{ml}$ toluene) was injected into the reactor at a point where the temperature was $200{ }^{\circ} \mathrm{C}$. The deposition was carried out for 1 and $2 \mathrm{~h}$, respectively. Argon was used as the carrier gas. After completion of the reaction, the $\mathrm{CF}$ cloth was removed from the furnace and weighed for estimating the amount of MWCNT filaments grown on the CF cloth.

In another set of experiments, as received $\mathrm{CF}$ cloth (without soaking in the ferrocene and toluene solution) was placed inside the tube furnace followed by injection of toluene-ferrocene mixture for the growth of MWCNTs for $2 \mathrm{~h}$ under identical conditions.

\section{Characterization}

The as grown CNTs on CF cloth prepared by different technique and duration were characterized using scanning electron microscope (SEM, Zeiss EVO MA-10) to understand the growth mechanism. To further characterize, TEM studies were carried out by scrapping the CNTs from CF cloth, dispersing them in acetone and drop casting one drop of solution on carbon-coated copper grids. TEM studies were carried out using Technai G20-stwin, $300 \mathrm{kV}$ instrument.

\section{Results and discussion}

\section{Growth mechanism of MWCNT filament}

On the basis of basic concepts of CNTs growth by catalytic CVD technique and SEM measurements, we have proposed a formation mechanism of CNT filaments and is schematically depicted in Fig. 1. Initially ferrocene particles (clusters of ferrocene particles) get deposited in the gap between $\mathrm{CF}$ tows. When the desired temperature $\left(750{ }^{\circ} \mathrm{C}\right)$ was reached, nucleation of the CNTs occured in the catalyst clusters and CNT filament formation started. Growth of filament continues because of continuous supply of ferrocene-toluene mixture in the reactor. Growth took place in the filament form because of the presence of ferrocene in the cluster form (not as individual particles). When the reaction time was increased from 1 to $2 \mathrm{~h}$; the filaments started growing in curved or coiled form as shown in the scheme as well as in SEM images. 
Fig. 1 Schematic representation of growth mechanism of CNT filaments on the surface of $\mathrm{CF}$ cloth

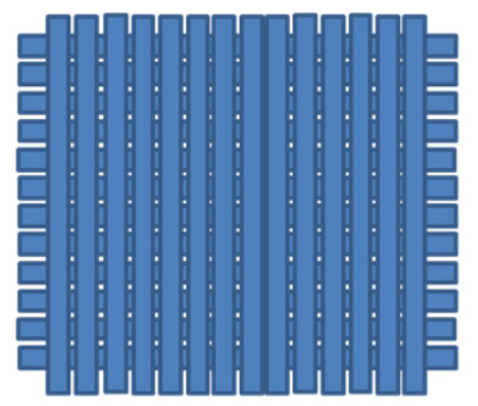

As Such CF Cloth

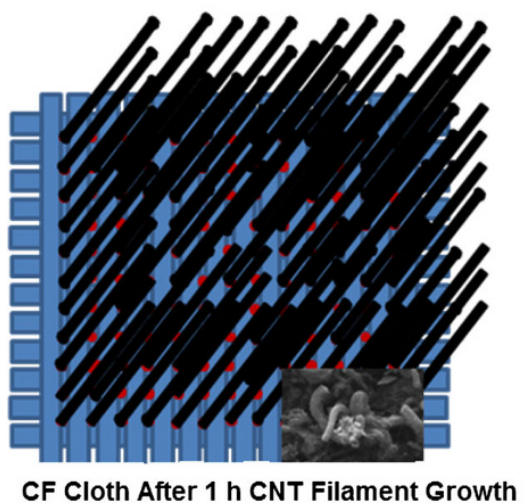

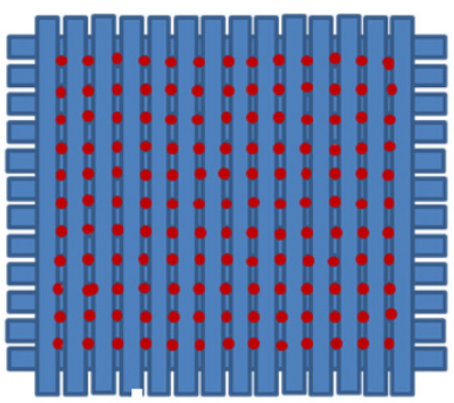

CF Cloth After Ferrocene Deposition

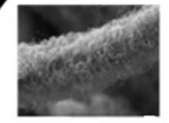

CNT Filament After $1 \mathrm{~h}$ Growth

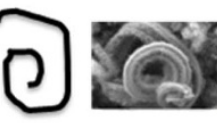

CNT Filament After $2 \mathrm{~h}$ Growth

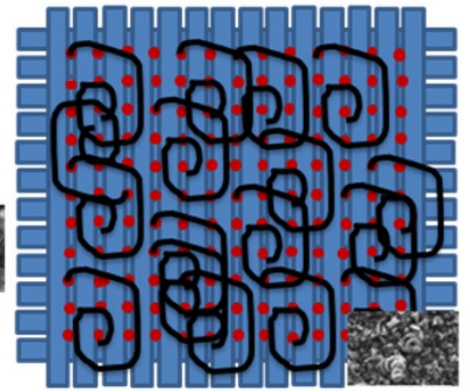

CF Cloth After 2 h CNT Filament Growth

\section{SEM/TEM of CNT filaments on CF cloth}

The surface morphology of the nanotubes in the form of filaments was investigated using SEM and the results for the samples grown for 1 and $2 \mathrm{~h}$ using method 1 are shown in Figs. 2 and 3, respectively. Figure 2a shows the optical microscopic image of plain weave CF cloth and Fig. 2b shows the SEM image of the CNT filaments layer deposited on the CF cloth using method 1 and for $1 \mathrm{~h}$ (on CF cloth coated with ferrocene). The SEM image is clearly revealing the copious growth of CNT filaments and is densely packed.

Figure 2c, d shows the magnified SEM images of samples grown for $1 \mathrm{~h}$ by method 1 . These images clearly reveal the uniform growth of filament. The diameter of the filaments varies from 15 to $25 \mu \mathrm{m}$. According to the proposed growth mechanism, the filament growth depends on the presence of ferrocene clusters/particles in the gap between the CF tows. The size of the filament depends on the size of the ferrocene cluster/particles in the gap. The filaments shown in Fig. 2c, d, nucleated from the ferrocene clusters available at various sites of the CF cloth placed inside the furnace at $750{ }^{\circ} \mathrm{C}$. The length of these filaments is very high which cannot be so unless catalyst particles coming through the injection of ferrocene-toluene solution also participate. Further magnified SEM image (Fig. 2e) shows the individual CNT.
The further characterization of the scraped materials from the CF cloth was carried out using TEM. The TEM image is shown in Fig. 2f. The multiwalled structure of CNTs can be clearly seen in the TEM micrograph. These MWCNTs are densely packed. Except the presence of few catalytic particles which are source of growth, MWCNTs were free from impurities.

When the growth was carried out for $2 \mathrm{~h}$, the structure of the filament was quite different from the samples grown for $1 \mathrm{~h}$. Figure 3 shows the structure of CNT filament grown for $2 \mathrm{~h}$ on $\mathrm{CF}$ cloth. It has been observed that up to $1 \mathrm{~h}$ of growth, slightly straight CNT filaments were formed, but after certain time it does not continue in similar fashion and CNT filaments having helical shape were observed. In SEM image, many such filaments are seen. The diameter is almost similar to sample grown for $1 \mathrm{~h}$, i.e., $15-25 \mu \mathrm{m}$ (Fig. 3a, b). Magnified SEM images (Fig. 3c) show that filaments are made of CNTs having uniform diameter. It is evident that in both the cases $(1 \mathrm{~h}$, straight filament and $2 \mathrm{~h}$, coiled filament), filaments are made of very uniform diameter CNTs. The coiled CNTs were further characterized by TEM and the results are shown in Fig. 3d. TEM micrograph is also confirming the presence of MWCNTs. The diameter of CNTs does not depend upon the diameter of ferrocene cluster but it depends upon the size of individual ferrocene particle 

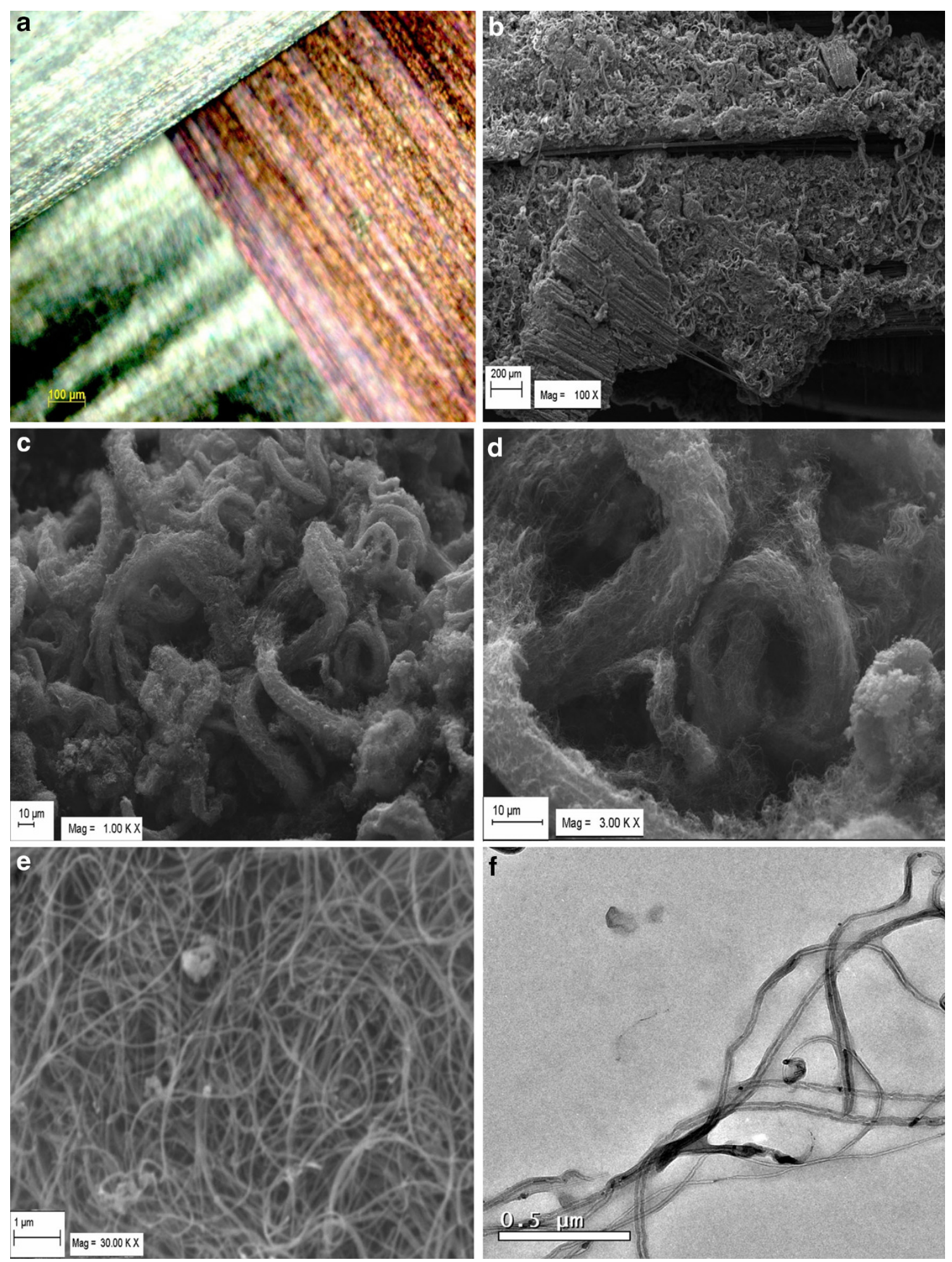

Fig. 2 a Optical micrograph image of CF cloth, b-e SEM image of CNT filaments grown on CF cloth for 1 h by method 1, and $\mathbf{f}$ TEM image of MWCNTs scraped from the CF cloth grown for $1 \mathrm{~h}$ by method 1 

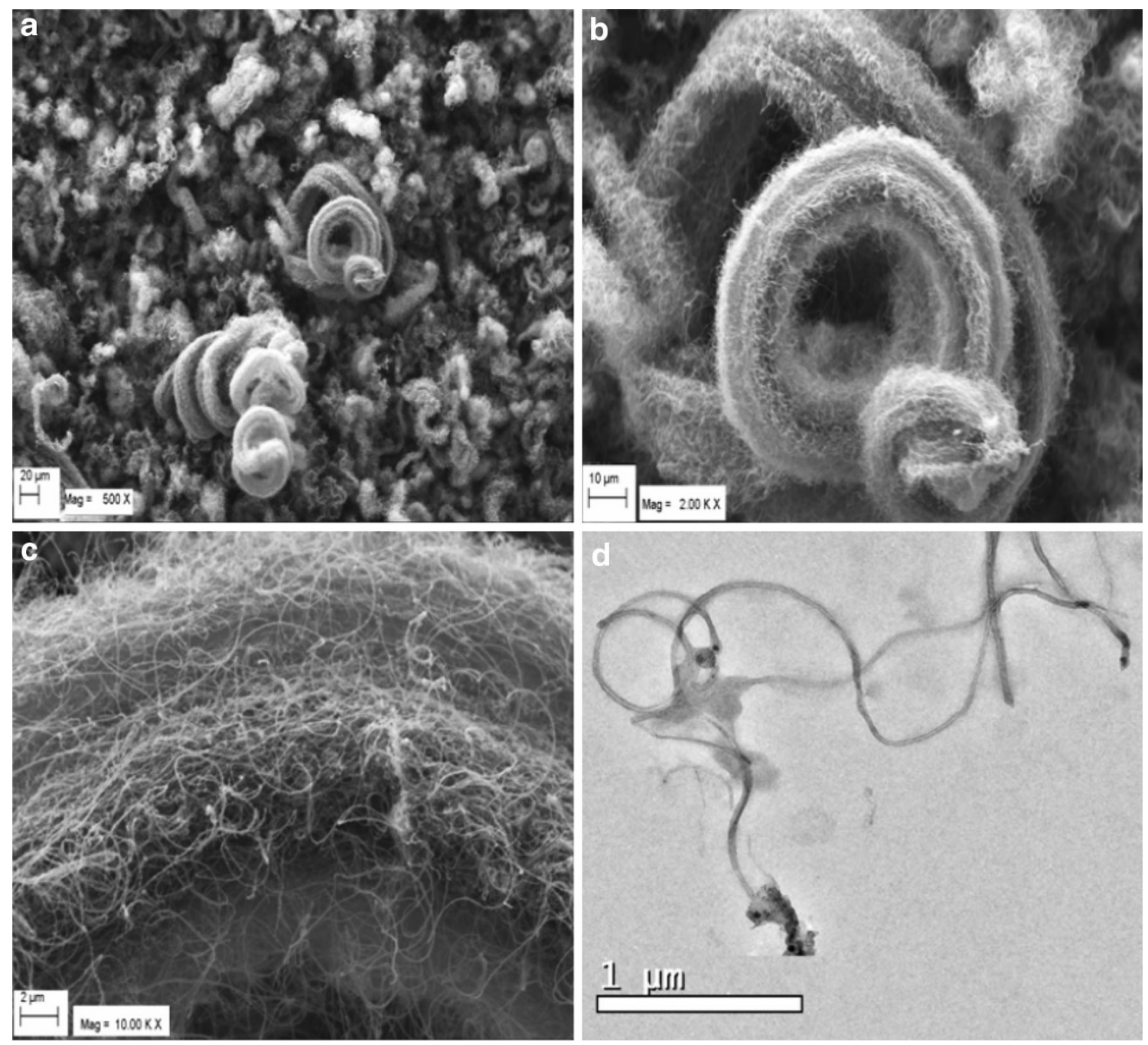

Fig. 3 a-c SEM image of CNT filaments grown on CF cloth for 2 h by method 1, d HRTEM image of MWCNTs scraped from the CF cloth grown for $2 \mathrm{~h}$ by method 1

and, therefore, the diameter of CNTs in the filaments is nearly similar in both the cases $(1$ and $2 \mathrm{~h})$. The diameters of the individual ferrocene particle in both the cases are similar. Therefore, the growth time is the only parameter to influence the structure of filaments.

When the MWCNTs were grown on CF cloth substrate by method 2 (without coating the CF cloth with ferrocene) for $2 \mathrm{~h}$, the structure is entirely different than sample grown by method 1 . In this case, growth of only CNTs took place which was confirmed by SEM (Fig. 4a-c) and TEM images (Fig. 4d). Figure 4a shows that the entire CF cloth substrate was covered with CNTs. The mechanism of the growth of this type of CNTs is different. Here, ferrocenetoluene mixture was passed through the reactor chamber. The ferrocene-toluene mixture produced individual $\mathrm{Fe}$ particle and $\mathrm{C}$ particle. The individual $\mathrm{Fe}$ particles got deposited on the CF substrate and after that carbon particle diffused through the Fe particle and individual tube was formed.

\section{Conclusions}

MWCNTs were synthesized on CF cloth by two different methods and for growth times ( 1 and $2 \mathrm{~h}$ ). In one method, first ferrocene particles were deposited on the CF cloth and CNTs growth occured with the help of additional available ferrocene + toluene mixture. Using this method, $1 \mathrm{~h}$ deposition time was sufficient for the growth of straight CNT filaments having diameter ranging from 15 to $25 \mu \mathrm{m}$ and length $>200 \mu \mathrm{m}$. When the samples were grown for $2 \mathrm{~h}$, CNT filaments in the form of coiled structure were obtained. In another method, when CF cloth without ferrocene was used, only CNTs (without filament formation)

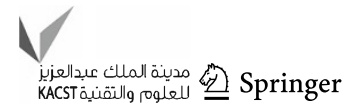



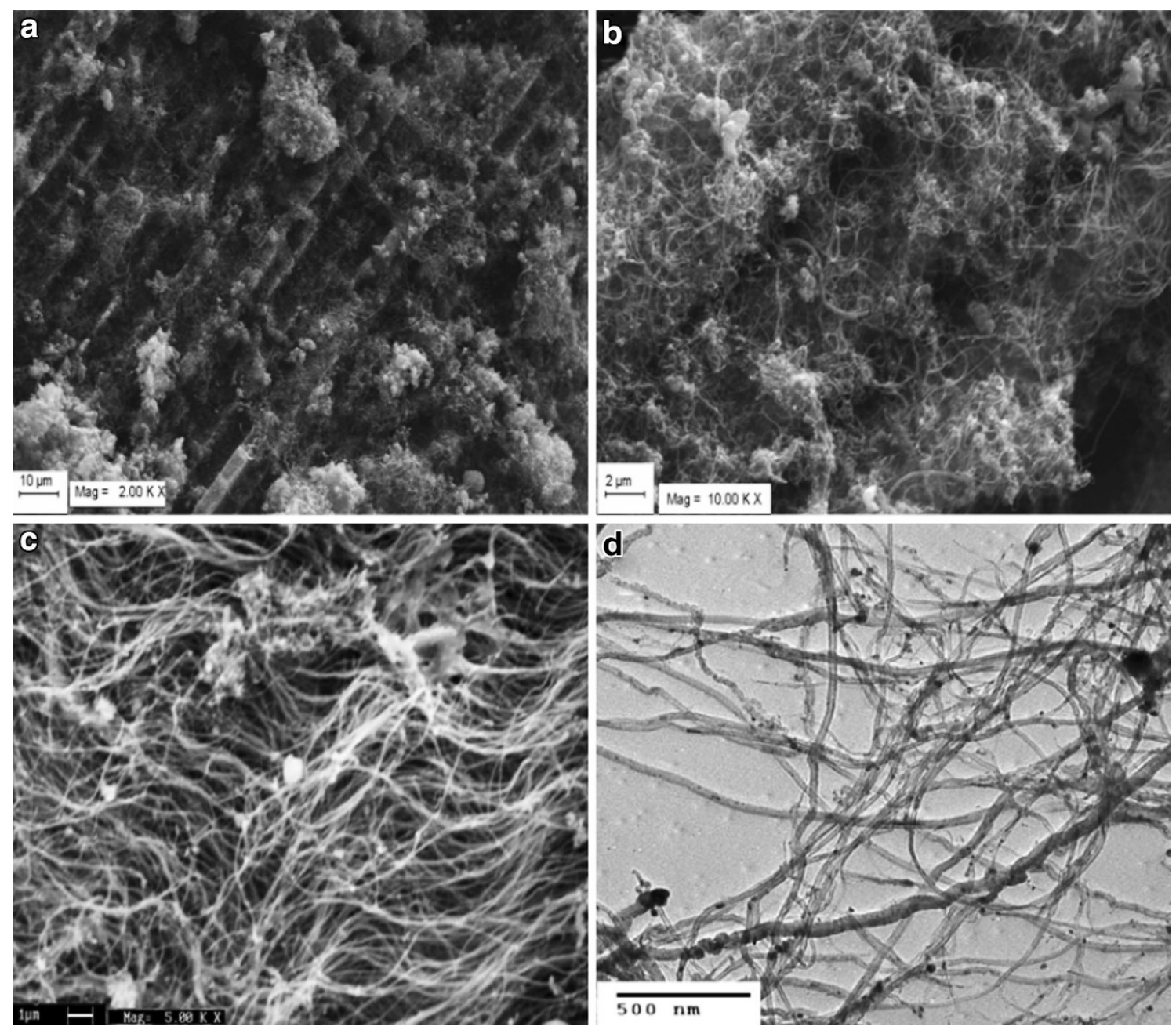

Fig. 4 a-c SEM image of CNT filaments grown on CF cloth for $2 \mathrm{~h}$ by method 1, d HRTEM image of MWCNTs scraped from the CF cloth grown for $2 \mathrm{~h}$ by method 2

were obtained. It shows that using ferrocene-coated $\mathrm{CF}$ cloth, good quality CNT filaments can be obtained only in $1 \mathrm{~h}$ which can be used for enhancing the structural properties when used in CNT-polymer composites.

Acknowledgments The authors wish to express their gratitude to Prof. R.C. Budhani, Director NPL, to accord his permission to publish the results. Authors would like to Mr. K.N. Sood and Mr. Jay Tawale for their support in carrying out SEM.

Open Access This article is distributed under the terms of the Creative Commons Attribution License which permits any use, distribution, and reproduction in any medium, provided the original author(s) and the source are credited.

\section{References}

Ago H, Ohshima S, Tsukuagoshi K, Tsuji M, Yumura M (2005) Formation mechanism of carbon nanotubes in the gas-phase synthesis from colloidal solutions of nanoparticles. Curr Appl Phys 5:128-132
Ajayan PM, Zhou OZ (2000) Application of carbon nanotubes. In: D. G, Dresselhaus MS, Avouris P (eds) "Carbon Nanotubes synthesis, structure, properties and applications". Springer, Berlin, pp 391-425 Andrews R, Jacques D, Rao A, Derbyshire F, Qian D, Fan X, Dickey E, Chen J (1999) Continuous production of aligned carbon nanotubes: a step closer to commercial realization. Chem Phys Lett 303:467-474

Biercuk MJ, Llaguno MC, Radosavljevic M, Hyun JK, Johnson AT, Fischer JE (2002) Carbon nanotube composites for thermal management. Appl Phys Lett 80:2767-2769

Chen Y, Sun Z, Li YN, Tay BK (2006) Optimization of carbon nanotube powder growth using low pressure floating catalytic chemical vapor deposition. Mater Chem Phys 98:256-260

Cheng HM, Li F, Su G, Pan HY, He LL, Sun X, Dresselhaus MS (1998) Large-scale and low-cost synthesis of single-walled carbon nanotubes by the catalytic pyrolysis of hydrocarbons. Appl Phys Lett 72:3282-3284

Chhowalla M, Teo KBK, Ducati C, Rupesinghe NL, Amaratunga GAJ, Ferrari AC, Roy D, Robertson J, Milne WI (2001) Growth process conditions of vertically aligned carbon nanotubes using plasma enhanced chemical vapor deposition. J Appl Phys 90:5308-5317

Choudhary V, Singh BP, Mathur RB (2013) Carbon Nanotubes and Their Composites. In: Satoru S (ed) Carbon nanotubes and their 
composites, syntheses and applications of carbon nanotubes and their composites. InTech, doi:10.5772/52897 (ISBN: 978-95351-1125-2)

Dai H, Rinzler AG, Nikolaev P, Thess A, Colbert DT, Smalley RE (1996) Single-wall nanotubes produced by metal-catalyzed disproportionation of carbon monoxide. Chem Phys Lett 260:471-475

Dhand C, Arya SK, Singh SP, Singh BP, Datta M, Malhotra B (2008) Preparation of polyaniline/multiwalled carbon nanotube composite by novel electrophoretic route. Carbon 46:1727-1735

Ebbesen TW, Ajayan PM (1992) Large-scale synthesis of carbon nanotubes. Nature 358:220-222

Ebbesen TW, Hiura H, Fujita J, Ochiai Y, Matsui S, Tanigaki K (1993) Patterns in the bulk growth of carbon nanotubes. Chem Phys Lett 209:83-90

Ericson LM, Fan H, Peng H, Davis VA, Zhou W, Sulpizio J, Wang Y, Booker R, Vavro J, Guthy C, Parra-Vasquez ANG, Kim MJ, Ramesh S, Saini RK, Kittrell C, Lavin G, Schmidt H, Adams WW, Billups WE, Pasquali M, Hwang W-F, Hauge RH, Fischer JE, Smalley RE (2004) Macroscopic, neat, single-walled carbon nanotube fibers. Science 305:1447-1450

Guo T, Nikolaev P, Thess A, Colbert DT, Smalley RE (1995) Catalytic growth of single-walled nanotubes by laser vaporization. Chem Phys Lett 243:49-54

Gupta TK, Singh BP, Teotia S, Katyal V, Dhakate SR, Mathur RB (2013a) Designing of multiwalled carbon nanotubes reinforced polyurethane composites as electromagnetic interference shielding materials. J Polym Res 20:1-7

Gupta TK, Singh BP, Dhakate SR, Singh VN, Mathur RB (2013b) Improved nanoindentation and microwave shielding properties of modified MWCNT reinforced polyurethane composites. J Mater Chem A 1:9138-9149

Jindal P, Pande S, Sharma P, Mangla V, Chaudhury A, Patel D, Singh BP, Mathur RB, Goyal M (2013) High strain rate behavior of multi-walled carbon nanotubes-polycarbonate composites. Compos B Eng 45:417-422

Li Y-L, Kinloch IA, Windle AH (2004) Direct spinning of carbon nanotube fibers from chemical vapor deposition synthesis. Science 304:276-278

Lubineau G, Rahaman A (2012) A review of strategies for improving the degradation properties of laminated continuous-fiber/epoxy composites with carbon-based nanoreinforcements. Carbon 50:2377-2395

Mathur RB, Seth S, Lal C, Rao R, Singh BP, Dhami TL, Rao AM (2007) Co-synthesis, purification and characterization of singleand multi-walled carbon nanotubes using the electric arc method. Carbon 45:132-140

Mathur R, Chatterjee S, Singh B (2008) Growth of carbon nanotubes on carbon fibre substrates to produce hybrid/phenolic composites with improved mechanical properties. Compos Sci Technol 68:1608-1615

Mathur RB, Singh BP, Dhami TL, Kalra Y, Lal N, Rao R, Rao AM (2010) Influence of carbon nanotube dispersion on the mechanical properties of phenolic resin composites. Polym Compos 31:321-327

Mathur RB, Singh BP, Tiwari PK, Gupta TK, Choudhary V (2012) Enhancement in the thermomechanical properties of carbon fibre-carbon nanotubes-epoxy hybrid composites. Int J Nanotechnol 9:1040-1049

Meenakshi KS, Sudhan EPJ (2011) Development and study of the thermal and electrical behaviour of TGDDS epoxy nanocomposites for high-performance applications. Appl Nanosci $1: 109-115$

Pande S, Mathur RB, Singh BP, Dhami TL (2009a) Synthesis and characterization of multiwalled carbon nanotubes-polymethyl methacrylate composites prepared by in situ polymerization method. Polym Compos 30:1312-1317

Pande S, Singh BP, Mathur RB, Dhami TL, Saini P, Dhawan SK (2009b) Improved electromagnetic interference shielding properties of MWCNT-PMMA composites using layered structures. Nanoscale Res Lett 4:327-334

Ruban YJB, Mon SG, Roy DV (2013) Mechanical and thermal studies of unsaturated polyester-toughened epoxy composites filled with amine-functionalized nanosilica. Appl Nanosci $3: 7-12$

Shenogin S, Bodapati A, Xue L, Ozisik R, Keblinski P (2004) Effect of chemical functionalization on thermal transport of carbon nanotube composites. Appl Phys Lett 85:2229-2231

Singh BP, Singh D, Mathur RB, Dhami TL (2008) Influence of surface modified MWCNTs on the mechanical, electrical and thermal properties of polyimide nanocomposites. Nanoscale Res Lett 3:444-453

Singh BP, Saini P, Gupta TK, Garg P, Kumar G, Pande I, Pande S, Seth RK, Dhawan SK, Mathur RB (2011) Designing of multiwalled carbon nanotubes reinforced low density polyethylene nanocomposites for suppression of electromagnetic radiation. J Nanopart Res 13:7065-7074

Singh BP, Choudhary V, Saini P, Mathur RB (2012a) Designing of epoxy composites reinforced with carbon nanotubes grown carbon fiber fabric for improved electromagnetic interference shielding. AIP Adv 2:022151-022156

Singh K, Singh BP, Chauhan R, Basu T (2012b) Fabrication of amperometric bienzymatic glucose biosensor based on MWCNT tube and polypyrrole multilayered nanocomposite. J Appl Polym Sci 125:E235-E246

Singh BP, Bharadwaj P, Choudhary V, Mathur RB (2013a) Enhanced microwave shielding and mechanical properties of multiwall carbon nanotubes anchored carbon fiber felt reinforced epoxy multiscale composites. Appl Nanosci, pp 1-8. doi:10.1007/ s13204-013-0214-0

Singh BP, Choudhary V, Saini P, Pande S, Singh VN, Mathur RB (2013b) Enhanced microwave shielding and mechanical properties of high loading MWCNT-epoxy composites. J Nanopart Res $15: 1-12$

Thess A, Lee R, Nikolaev P, Dai H, Petit P, Robert J, Xu C, Lee YH, Kim SG, Rinzler AG, Colbert DT, Scuseria GE, Tománek D, Fischer JE, Smalley RE (1996) Crystalline ropes of metallic carbon nanotubes. Science 273:483-487

Xie X-L, Mai Y-W, Zhou X-P (2005) Dispersion and alignment of carbon nanotubes in polymer matrix: a review. Mater Sci Eng R: Rep 49:89-112

Zhang M, Atkinson KR, Baughman RH (2004) Multifunctional carbon nanotube yarns by downsizing an ancient technology. Science 306:1358-1361 